\section{El documental independiente peruano}

\author{
José Balado
}

E 1 documental es uno de los géneE ros audiovisuales más antiguos y necesarios dentro del universo de las comunicaciones. Entendemos que el documental nace al mismo tiempo que el cine. Las primeras experiencias con las imágenes en movimiento tenían por objeto registrar acontecimientos de la vida cotidiana de las personas y de los animales. Así, la contribución de los pioneros del cine para el documental fue mostrar que el material base de trabajo son las imágenes recogidas en los lugares donde ocurren los acontecimientos. $\mathrm{O}$, dicho de otra forma, es el registro in loco que encontramos en el inicio del cine, que constituye la raíz (principio base) en la que se asienta la producción documental.

En los años veinte se crearon las condiciones para la definición del género documental, más concretamente con Robert Flaherty (1884-1951) y Dziga Vertov (1895-1954). Estos dos cineastas abrirán camino para los documentales, definiéndoles un posicionamiento. En primer lugar, confirmaron que era absolutamente esencial que las imágenes del filme hablen respecto de lo que tiene existencia fuera del filme, es decir, el documentalista debe salir del estudio y registrar in loco la vida de las personas y los acontecimientos del mundo. A esta obligación, el documentalista puede responder de diversas formas. Los dos cineastas mencionados son ejemplo de ello: si el primero pedía a las per- 
sonas que se manifestaran para su cámara, el segundo pretendía captar a las personas en su vida cotidiana, preferentemente sin que se dieran cuenta de que estaban siendo filmadas. Más aún, es indispensable que ese material sea sometido a una reflexión, en especial en el montaje de la película. El documental no es un mero "espejo de la realidad", no representa la realidad tal cual; al combinar e interrelacionar las imágenes obtenidas in loco estamos contribuyendo a dar un significado a la realidad y es precisamente eso lo que se pretende que sea un documental.

En conclusión, Flaherty y Vertov mostraron que es posible que exista un filme donde el registro del mundo y la reflexión de ese mundo o la reflexión de ese registro ocupen un lugar privilegiado. Además, en esas primeras décadas fueron producidos documentales disímiles en formas narrativas y en aproximaciones al sentido formal y en cuanto al objetivo y finalidad del quehacer documental. Lenni Riefenstahl, Luis Buñuel, Sergei Eisenstein, Joris Ivens, Walter Ruttman, John Huston, Pier Paolo Pasolini, entre otros, mostraron las posibilidades políticas, propagandísticas y sociales del género desde sus comienzos.
El documental en cuanto género con una identidad propia, autónomo y distinto de los restantes, solo conoce las condiciones necesarias para su afianzamiento y reconocimiento en cuanto tal en los años treinta, con el movimiento documentalista británico y, en especial, con su figura más emblemática: John Grierson (1898-1972). En estos años encontramos una efectiva producción de filmes designados como documentales.

Los escritos de Grierson, especialmente el artículo escrito en 19321934, "First Principles of Documentary"1 establece para el documental una identidad propia. Antes que nada, dice que se trata de un filme de categoría superior en relación con las restantes producciones que también usan material recogido de la realidad. En los "filmes de hechos" ("factual films") impera la mera descripción y exposición de hechos. Por el contrario, en el documental, por él definido como un "tratamiento creativo de la realidad", hay combinaciones, recombinaciones y formas creativas de trabajar el material recogido en el lugar de los hechos.

El documental trabaja sus temas de modo creativo, revelando algo sobre los fenómenos, en su caso, los fenóme-

1 FORSYTH, Hardy. Grierson on documentary. Londres: Faber \& Faber, 1979. 
nos tratados eran los problemas sociales y económicos vividos en Gran Bretaña en los años treinta. Las temáticas debían ser presentadas según un determinado punto de vista. Grierson nos habla de "revelar la realidad del objeto tratado" de "crear una interpretación". Esa interpretación, a la que yo llamo punto de vista, recae sobre las temáticas abordadas en los filmes y registradas in loco. Grierson entendía que los documentales debían tener una función social, pedagógica y de educación cívica, y la producción de su "escuela" -instalada en las Film Units subvencionadas por el gobierno- dependía de la financiación gubernamental. Por eso los filmes usaban la voz en off y tenían una estructura llamada "problemmoment". O sea, los problemas eran presentados como si fueran un mero momento de crisis por el que el país estaba atravesando y que iba a ser solucionada por el gobierno. En los documentales producidos en las Film Units eran presentadas las soluciones gubernamentales para cada uno de los problemas abordados.

Grierson reconoce que el documental podría tratar diferentes temáticas, para cada una de las cuales es posible organizar el material del filme de diversas formas. Cada una de esas formas corresponde a puntos de vista diferentes sobre un mismo tema. Este reconocimiento inicial es inmediatamente olvidado por la fuerza con la que defiende para el documental una fun- ción social. Esta característica que no es del todo inherente al documental lo marcó profundamente. O sea, el documental es conocido como un género que usa voz en off —esta es una de las razones por las que generalmente se confunde con el reportaje- y que trata temáticas de relevancia social (sobre esta cuestión debemos decir que la actual producción de documentales, felizmente, nos muestra que este es un género que favorece la diversidad de temáticas y formas).

Grierson también confiere un estatuto especial al documentalista. Estando el documental apartado de la mera reproducción de los acontecimientos, el autor del filme interviene de modo creativo en su realización: se asume como un artista. Sin embargo, esa intervención es controlada por el propio Grierson en cuanto productor de las Film Units; por ejemplo, EMB (Empire Marketing Board) y GPO (General Post Office), donde desarrolló su trabajo en el sentido de garantizar la financiación estatal. La escuela de Grierson confronta la creatividad con el patrocinio gubernamental.

De todos modos, con Grierson quedó definitivamente clarificado que para llamar documental a un determinado filme no basta que ese filme exhiba solo lo que los hermanos Lumière nos mostraron: que el mundo puede llegar hasta nosotros por el mirar de la cámara. Es muy importante que el autor de 
las imágenes ejerza su punto de vista sobre esas imágenes. Es necesaria la confrontación de otro mirar, el mirar del documentalista que se constituye como el punto de vista sobre determinado asunto. Es necesario también que el documental sea una confrontación entre esos dos mirares: la cámara y el documentalista. Más aún, el documental debe pautarse por la creatividad en cuanto a la forma de sus imágenes, sonidos, o cualquier otro elemento organizado.

Podríamos mencionar que es a partir de este momento cuando el eje documentalista y realidad se diluye y se adentra en nuevos confines narrativos y de puntos de vista. Es el documental no visto como una mera ventana al mundo, sino mostrando cómo el documentalista ve esa ventana al mundo. Lo que se eleva a primer nivel es el punto de vista, es la forma como el ojo del documentalista registra, conversa y digiere la realidad que lo circunda. Fueron autores como Jean Renoir, Frederick Wiseman, Chris Marker, Jean Rouch, Fernando Solanas, Patricio Guzmán, Trin T. Min-Ha, Richard Leacock, entre otros, los que nos ayudaron a entender las nuevas perspectivas que se abrían dentro de las posibilidades del género. Un nuevo documental donde el punto de vista del autor, su interpretación creativa de la realidad trabajada o registrada, serían los pilares fundamentales para colocar en la justa perspectiva la relación realidad y registro. Forma y contenido, al igual que proceso y producto documental, ya no serían más ejes o polos, sino fronteras diluidas y dinámicas del mismo quehacer.

Se puede decir, grosso modo, que el documentalismo tiene tres principios: la obligatoriedad de hacer un registro in loco de la vida de las personas y de los acontecimientos del mundo; debe presentar las temáticas a partir de un determinado punto de vista; y, finalmente, el documentalista debe tratar con creatividad el material recogido en el lugar de los hechos, pudiendo combinarlo con otro material; por ejemplo, leyendas, otro tipo de imágenes o formas narrativas provenientes de otras disciplinas. Comenzamos a entender el documental como una forma híbrida que abarca diferentes opciones narrativas, que diluye la frontera entre ficción y realidad, que coloca al documentalista como prisma por el cual miramos el tema, la realidad y sus actores.

Teniendo como punto de partida el estilo del documental en cuanto género, es posible averiguar su desarrollo como un producto interactivo. Debemos también tener en cuenta el pasado histórico del documental. En este punto podremos decir que después de los años treinta, lo más importante que se verificó en la historia del documental fue la revolución tecnológica que transcurrió en los años cincuenta y sesenta, 
y que consistió en la introducción y utilización de cámaras y sonido sincronizado portátiles. Esta, entonces nueva tecnología, permitió, por ejemplo, la realización de entrevistas en la calle (como vemos en el filme de Jean Rouch titulado Chronique d'un Été, 1960). Ese nuevo equipamiento, que sustituyó el uso del de 35 milímetros, permitió una mayor y diversificada producción de documentales. Nuevas estrategias, nuevos estilos, nuevas formas del género documental tomaron vida, y entre ellos encontramos los trabajos etnográficos de Rouch o el llamado Direct Cinema norteamericano.

Si el desarrollo de la tecnología en las décadas de 1950 y 1960 tuvo una importancia primordial en la historia del documental, hoy somos testigos de otro otro avance de este tipo. Concretamente, la abolición del soporte analógico por el soporte digital. Este cambio no debe ser ignorado por el documentalismo. Para el documentalista, las tecnologías informáticas son un soporte más para el "tratamiento creativo de la realidad" y para ubicar este nuevo cambio nos colocaremos en la reciente producción documental independiente peruana.

\section{El documental en el Perú}

No es la intención de este artículo hacer un recuento o panorama de la historia o producción documental en el país, sino más bien levantar varios puntos de interés acerca de esta nueva producción de jóvenes documentalistas provenientes de los centros universitarios, así como de producciones realizadas de forma independiente en el país; asimismo, anotar los nuevos espacios para la producción, proyección y discusión de este género en el Perú.

En los últimos años, la actividad documental en el país se ha incrementado cualitativa y cuantitativamente. Los centros académicos están jugando un rol importante dentro de la producción actual. La Universidad de Lima y las universidades Católica, Ricardo Palma, San Ignacio de Loyola y San Marcos, y el Instituto Toulouse Lautrec, entre otros centros académicos, han desarrollado talleres documentales que sirven como agentes catalizadores de una voluntad estudiantil de rever y colocarse en la historia y la coyuntura actual nacional. Del mismo modo, han surgido nuevas casas productoras, grupos de trabajo y organizaciones que ven en el género documental una forma de registrar y promover temas importantes en la palestra pública.

Cuando hablamos de colocarse y de rever su país nos referimos a temáticas tanto políticas como sociales, temáticas que trabajan con materias como el olvido, la memoria, la historia revisitada, temas ecológicos, de denuncia social y de reivindicación de problemas comunitarios, de colocar al 
ciudadano y al individuo frente a la realidad de un sistema que no representa ni toma en cuenta las verdaderas necesidades básicas de cualquier sociedad. Temas que intentan levantar y comentar las injusticias de un sistema y de una sociedad frente a las minorías y a la gran masa del país: los desprotegidos e indigentes y las clases subalternas.

Pero lo interesante de esta nueva etapa documental no es solamente la preocupación por los temas antes expuestos, sino que surgen nuevos relatos, nuevos puntos de vista, donde lo social, la tolerancia, la desigualdad, la injusticia y los demás males sociales, atraviesan el espacio personal, llevando el pensamiento y la práctica política a niveles de ese universo tan infinito y complicado que es el espacio personal y cotidiano. Son documentales reflexivos, en los que lo personal es lo político, donde el punto de vista o la temática o forma seleccionada están intrínsecamente relacionados con la situación o punto de vista del realizador. Abordan temas como la sexualidad y sus diferentes manifestaciones, la cultura viva del país, las tradiciones que pasan por la historia oral o familiar, la geografía urbana, la cultura pop, la cultura underground, asuntos que trabajan el cuerpo, la represión, la tolerancia o intolerancia, problemáticas de género y de la posición de la mujer en nuestra sociedad, la situación y punto de vista de los jóvenes y de los niños y un sinnúmero de nuevas manifestaciones encontradas en el Perú de hoy.

Dentro de este panorama podemos hablar de las nuevas voces o formas narrativas utilizadas por el movimiento independiente. Voces reflexivas que se cuestionan el propio quehacer documental, nuestra ubicación, nuestra información y nuestra propia estructura y prejuicios. Un nuevo documental donde no está dicha ni completada la historia, un género que se desarrolla y crece en sus propias limitaciones técnicas y narrativas. Nuevas voces sin prejuicios por las formas, sin miedo a descubrir y sobre todo sin miedo a la búsqueda de posibles soluciones a las historias individuales y colectivas. Documentales realizados en diferentes escenarios de producción, proyectados a públicos diferentes y, mejor aún, con formas narrativas y modelos de producción completamente disímiles. La nueva producción documental peruana siente la necesidad de hablar, de dialogar y de presentar historias, ya sean políticas o personales, de una manera ágil e innovadora, llevando el producto documental a nuevos públicos, donde la proyección y la discusión son reflejo de la necesidad de crear nuevos espacios para ejercitar la memoria y la tolerancia. Y el documental es uno de los géneros por excelencia para el ejercicio de la democracia. El documental es el arte de reivindicar y rectificar y es aquí donde las actuales historias y formas de producción se insertan. Son 
voces y puntos de vista variados, geografías que transitan desde la región Q'ero en Paucartambo y Huancayo, hasta Pamashto y Pucallpa en la selva peruana, pasando por el Jirón de la Unión en Lima y por Comas. Desde chamanes y curanderos de la sierra, hasta transexuales, drogadictos, grafiteros y raperos urbanos, el nuevo documental toma cuenta de las nuevas dinámicas y espacios sociales de una forma digital, accesible, directa. Desde las reflexiones personales, el uso de animación, de crónicas de viaje, de diarios y ensayos, de sinfonía de ciudad, de video-guerrilla, de video-verdad, de docurrepresentaciones, de docuhumor, de documusical y de otros tantos géneros, los nuevos realizadores de documental funden formas y experiencias anteriores con las nuevas tecnologías digitales. Es necesario aclarar que el documental es uno de los géneros que desde sus inicios nació con la experimentación, las formas vanguardistas, la transgresión y la búsqueda de lo no convencional. Los jóvenes documentalistas buscan en la historia documental internacional sus fuentes para crear sus propias formas. El documental antiguo no es National Geographic, por el contrario, los padres y los antecesores del documental digital se encontraban en la búsqueda de adecuar temas documentales con sus miradas personales, tanto en forma como en contenido. Por eso la variedad temática y la búsqueda de las voces internas son una constante en la historia documental, y ese espíritu es el examinado en el movimiento independiente peruano.

Es justo en la presente coyuntura donde se abre paso una nueva variable importante en el surgimiento de este movimiento independiente: la nueva tecnología digital. Esta tecnología nos remite en cuanto a acceso, facilidad y abaratamiento, a reestructurar el quehacer y el producto documental. Como mencionamos, equivalente a dicha revolución digital, encontramos la experiencia de los años cincuenta con la llegada de equipo fílmico más liviano y sincronizado, que permitía crear nuevas formas documentales. La posibilidad de un documental digital en nuestra realidad posibilita la producción de un mayor número de proyectos y de capacidad de intercambiar y mostrar dichos proyectos en los ámbitos nacional e internacional.

Jóvenes realizadores(ras) que retoman la frase de Glauber Rocha, padre del Cinema Novo brasileño, cuando dijo: "Para hacer cine solo hace falta una idea en la cabeza y una cámara en la mano". Esta frase encierra esta primera etapa del nuevo movimiento documentalista independiente. Una primera etapa que intenta redescubrir las dimensiones sociales e históricas del país y las contradicciones y prácticas encontradas en la vida cotidiana. Un documental que abraza el formato digital en todas sus manifestaciones y lo 
lleva a las diferentes regiones y calles del país. Proyecto documental que se construye por el oficio pero que debe nacer y crecer. Esta primera etapa es fructífera en cuanto a cantidad y variedad se refiere. Ahora se hace imperativo crear las estructuras y bases para la consolidación de un espacio documental y esta deberá ser la segunda etapa del nuevo movimiento, una etapa de proyección nacional e internacional, de participación en otros gremios o agrupaciones internacionales, el intercambio con profesionales del área en todos los renglones del quehacer documental, de capacitación técnico-narrativa, de creación de bases de datos y archivos de la memoria documental, de consolidación de redes de apoyo económico nacional e internacional al igual que de posibles coproducciones. Pero lo más importante es la tolerancia y el apoyo hacia las formas, procesos y proyectos documentales existentes, fomentando una cultura documental amplia y democrática, necesaria para adelantar y promover el quehacer documental. Recordemos la frase de Patricio Guzmán: "Un país sin producción documental es como una familia sin un álbum de fotos".

A continuación se enumeran algunos puntos importantes que caracterizan a esta segunda etapa del documental independiente peruano:

- La creación de nuevos espacios de proyección en los últimos años:
- La Noche de los Cortos;

- La Muestra de Cine de lo Real;

- La Muestra de Documentales Independientes Peruanos en el Centro Cultural de España;

- La Ventana Indiscreta de la Universidad de Lima y el Cinematógrafo de Barranco;

- Las diferentes municipalidades y sus ciclos de cine documental;

- Los nuevos espacios televisivos, especialmente de los canales $\mathrm{N}$, 6 у 7 ;

- El Encuentro de Cine Latinoamericano del Centro Cultural de la Pontificia Universidad Católica; y

- Las diferentes muestras en Lambayeque, Cusco, Arequipa, Piura, Ayacucho y otras regiones.

- Las universidades e institutos que comienzan a incluir talleres documentales dentro de sus currículos.

- Las diferentes organizaciones y entidades no gubernamentales que utilizan el documental como herramienta de comunicación.

- Los diferentes gremios, cooperativas o individuos que se aglutinan en torno al género.

- La creación del grupo virtual CinemaPerú.

- Los varios premios nacionales e internacionales adquiridos por documentalistas peruanos.

- El boom internacional que tiene el documental en los últimos años. 